\title{
MANAJEMEN SUMBER DAYA INSANI DI BMT UGT SIDOGIRI
}

\author{
Nuntupa ${ }^{a}$ \\ Mutamakkim Billahb \\ a,b Faculty of Islamic Economics and Business, Universitas Islam Zainul Hasan \\ Email: nuntufa42@gmail.com
}

\begin{abstract}
Introduction : Human resources in BMT UGT Sidogiri in Indonesia have an important role in the development of a company and demonstrate its service capabilities, as evidenced by the large number of customers who raise funds to BMT. The way to find human resources in BMT is by way of recruitment. Recruitment is an important aspect in finding human resources so that they can provide maximum service and performance. This study aims to determine the Human Resource Management at BMT UGT Sidogiri Kraksaan Branch.

Methods : This type of research is field research, which in essence is a method to find specifically and realistically what is happening at some point in the community. Meanwhile, the data analysis technique uses qualitative descriptive analysis techniques.

Results : The results of this study are as follows: First, the recruitment system at BMT UGT Sidogiri Kraksaan Branch is very good using two methods, namely internal and external recruitment. In addition, there are special considerations in the recruitment system, where these considerations are prioritized for prospective employees from the Sidogiri Islamic Boarding School Alumni who are not required to be graduates of sharia banking and sharia economics. Because the most important thing in being an employee of BMT UGT Sidogiri Kraksaan Branch is an inner bond so that it will create employees who have high loyalty to the organization. Therefore, from the use of these methods and special considerations, BMT can find human resources who have high loyalty and capabilities that can be developed. Second, while in the process of fulfilling the professional demands of BMT UGT Sidogiri Kraksaan Branch using a strategy by means of training and evaluation. Where the training is carried out at the end of the year which is carried out for 5 days and the evaluation is carried out every day for employees and every month for the head of BMT.
\end{abstract}

Keywords: Management, Human Resources, Recruitment, Performance

\section{PENDAHULUAN}

Sumber daya insani adalah istilah lain dari sumber daya manusia, dimana kata insani berarti ada sangkut pautnya dengan manusia, kemanusiaan atau manusiawi. Pengelolaan sumber daya insani (SDI) dalam peristilahan disebut juga dengan manajemen sumber daya manusia, dengan tujuan untuk mengetahui beberapa pendekatan yang ada sangkut pautnya dengan perbuatan para karyawannya ${ }^{1}$. Tujuan

1Jusmaliani, Pengelolaan Sumber Daya Insani, Jakarta: Bumi Aksara, 2014. 8. 
pelaksanaan pengelolaan sumber daya insani adalah untuk mencegah hal-hal yang tidak sesuai dengan keinginan seperti mempekerjakan karyawan yang tidak sesuai dengan pekerjaannya, turnover yang tinggi, serta memperoleh karyawan yang tidak melakukan pekerjaannya secara ideal atau efisien, menyia-nyiakan waktu.

Sumber daya insani menjadi sebuah perencanaan baru dalam ruang lingkup pekerjaan yang seharusnya diterapkan dan dilaksanakan di lembaga-lembaga yang berdasar syari'ah. Sistem keuangan syari'ah dirumuskan dari penggabungan dua dominasi yang mendasarinya, pertama yaitu dasar-dasar syar'i yang diambil dari alQur'an dan As-Sunnah, dan yang kedua yaitu dasar-dasar tabi'i yang merupakan hasil dari pandangan teoretis terhadap sesuatu dalam daya pikir manusia untuk menghadapi permasalahan dalam perekonomian. Bersamaan dengan kejadian-kejadian yang semakin berkembang di masyarakat saat ini, menjadikan semakin banyak kalangan masyarakat memilih untuk kembali ke ajaran agama. Banyaknya perusahaan atau instansi yang bergerak di bidang lembaga keuangan syari'ah yang berusaha menerapkan prinsip syari'ah Islam khususnya lembaga keuangan seperti Bank Pengkreditan Rakyat (BPR), Asuransi syari'ah (takaful) dan (BMT) ${ }^{2}$.

Dalam perkembangannya, lembaga keuangan syaria'ah yang sangat pesat khususnya di Indonesia seharusnya juga turut adanya perekrutan sumber daya insani yang berkompeten dalam bidang perbankan syari'ah. Lembaga keuangan syari'ah menyelenggarakan perekrutan karyawan untuk mewujudkan pembangunan sumber daya insani yang mempunyai kualitas yang baik, dimana untuk mempunyai kualitas tersebut dibutuhkan tenaga kerja berbasis Islami dengan jumlah 184.800 orang yang terdiri dari 8.400 (Doktor Ilmu Ekonomi Islam), 25.200 (Magister Ekonomi Islam), 50.400 (sarjana), dan 100.800 (tenaga ahli madya). Artinya tenaga profesional dalam perbankan syari'ah masih diisi oleh SDI dengan dasar keilmuan di bidang lain ${ }^{3}$. Pada tayangan Economic Challenges pada 7 Juni 2016 di Metro TV disampaikan bahwa berdasarkan datadata dari Bank Indonesia, sekitar 90\% tenaga kerja di perbankan syari'ah tidak memiliki latar belakang pendidikan ekonomi syari'ah.

BMT UGT Sidogiri merupakan salah satu lembaga keuangan syari'ah yang bertugas melakukan penghimpunan dana komersil berupa modal, simpanan dan lain-lain yang disalurkan pada usaha-usaha komersil. Sehingga dana tersebut menjadi produktif dan bernilai plus. Untuk melaksanakan semua itu BMT UGT Sidogiri membutuhkan Sumber Daya Insani yang berkompeten pada bidangnya untuk mencapai tujuannya. BMT UGT Sidogiri merupakan lembaga keuangan syari'ah seperti halnya lembaga-lembaga keuangan syari'ah pada umumnya yang merekrut Sumber Daya Insani (SDI) yang professional untuk menjadi anggota karyawannya.

\footnotetext{
2 Maryani, Ay. Analisis Pengaruh Kompetensi Syari'ah, Kompensasi Islami dan Kecerdasan Spiritual terhadap Kinerja Karyawan, Jurnal Vol 1, UIN Syarif, 2018.

${ }^{3}$ Syamsuddin AR, Vismaia S. Damaianti, Metode Penelitian Pendidikan Bahasa, Bandung: Remaja Roda Karya. 2011, 14.
} 
SDI di BMT UGT Sidogiri mengalami hal yang sama dalam kebutuhan menemukan pegawai dengan cara perekrutan. Namun dengan banyaknya pegawai BMT UGT Sidogiri yang bukan dari lulusan studi perbankan syari'ah ataupun ekonomi syari'ah yang mayoritas mengisi di dalam lembaga tersebut, dikarenakan BMT UGT Sidogiri lebih memprioritaskan para alumni pondok pesantren Sidogiri karena dasar yang dipegang oleh BMT UGT Sidogiri adalah jujur dan amanah. Dalam perekrutan tenaga kerja melalui prosedur rekrutmen secara administratif di BMT UGT Sidogiri yang harus di lampirkan adalah surat lamaran, fotocopy KTP, kartu keluarga, biodata diri, SKCK. Ijazah terakhir, dan foto warna. Serta penempatan tenaga kerja mempunyai ketergantugan terhadap keterampilan setiap tenaga kerja berdasarkan ketetapan yang telah di sesuaikan dengan ketentuan yang ada di BMT UGT Sidogiri.

\section{METODE PENELITIAN}

Metode penelitian merupakan cara penyelesaian suatu permasalahan dalam penelitian yang dilaksanakan secara terarah dan kehati-hatian dengan maksud mendapatkan fakta dan memahami, menjelaskan, memperkirakan Dan mengendalikan suatu keadaan. Metode juga merupakan suatu aktivitas yang dilakukan dengan maksud untuk memahami dan mendalami objek yang menjadi sasarannya. Dengan metode yang tepat, seorang peneliti tidak hanya mampu melihat fakta yang ada sebagai kenyataan tetapi juga mampu memperkirakan prospek yang dapat terjadi melalui fakta tersebut 4 . Penelitian ini dilaksanakan di Kantor BMT UGT Sidogiri Cabang Kraksaan yang berada pada ruang lingkup Pasar Semampir berada di Jalan MT Haryono No 408 Semampir Kecamatan Kraksaan Kabupaten Probolinggo, Jawa Timur. BMT ini memiliki letak geografis yang strategis, karena terletak di utara Pasar Semampir. Penelitian dengan metode kualitatif menggunakan jenis penelitian lapangan (field research) yang pada hakikatnya merupakan metode untuk menemukan secara khusus dan realistik apa yang tengah terjadi pada suatu saat di tengah masyarakat ${ }^{5}$. Dalam penelitian kualitatif kehadiran peneliti secara langsung di lokasi penelitian sangat diperlukan, karena peneliti harus menagkap makna dengan melakukan interaksi terhadap berbagai nilai di obyek penelitian, hal tersebut tidak dapat dilakukan dengan metode kuesioner atau alat pengumpul data lainnya, kerena peneliti disini bertindak sebagai Key Instrument sekaligus pengumpul data, sementara instrument dalam penelitian ini digunakan sebagai pendukung dan pembantu dalam pengumpul data. Dalam melakukan penelitian ini kedudukan peneliti adalah sebagai perencana, pelaksanaan, pengumpul data, penganalisis, penafsir data dan akhirnya sebagai pelapor hasil penelitian ${ }^{6}$. Dimana sumber data yang diperoleh nantinya menggunakan dua cara yaitu dengan data primer

\footnotetext{
${ }^{4}$ Aji Damanuri, Metodologi Penelitian Muamalah, Ponorogo: STAIN Po PRESS, 2010, 6.

5 Lexy J Moleong. "Metodelogi Penelitian Kualitatif", Bandung: PT. Remaja Rosdakarya, 2014, 3

${ }^{6}$ Lexy J Moleong. “Metodelogi Penelitian Kualitatif”, Bandung: PT. Remaja Rosdakarya, 2014, 3
} 
dan data sekunder yang dalam pengumpulan datanya menggunakan. Dokumentasi yaitu menganalisis dokumen-dokumen yang dibuat oleh subjek sendiri atau oleh orang lain yang berhubungan subjek. Berkaitan dengan ini penulis mendokumentasikan dan/atau mencari dokumen-dokumen serta hal-hal yang berkaitan erat dengan penelitian yaitu dokumen resmi, buku, majalah, arsip, ataupun dokumen pribadi, . wawancara deskriptif yaitu pertanyaan yang meminta narasumber untuk memberikan gambaran atau mendeskripsikan secara naratif tentang berbagai hal antara lain: meliputi kondisi BMT UGT Sidogiri Cabang Kraksaan saat ini, karakteristik sumber daya insani (SDI), penyaringan atau seleksi karyawan di BMT UGT Sidogiri Cabang Kraksaan, penempatan SDI di BMT UGT Cabang Kraksaan, memenuhi tuntutan profesionalitas di BMT UGT Sidogiri Cabang Kraksaan, peningkatan kualitas sumber daya insani, pembinaan kepada karyawan, Sumber Daya Insani (SDI) yang berkualifikasi syari'ah dan lain-lain7, 3. wawancara tidak berstruktur yaitu suatu wawancara yang leluasa dilakukan oleh peneliti, di mana peneliti tidak memakai panduan wawancara yang telah disusun secara sistematis atau terstruktur dan lengkap untuk pengumpulan datanya. Pedoman wawancara yang digunakan hanya berupa garis-garis besar permasalahan yang akan penulis tanyakan ${ }^{8}$.

Analisis yang dilakukan dalam penelitian ini adalah teknik analisis deskriptif kualitatif yaitu proses penyederhanaan data kedalam bentuk yang lebih mudah dibaca, dan di interpretasikan secara lebih spesifik dengan mengkaji secara mendalam hasil penelitian, serta data yang telah terkumpul akan diuraikan. Analisa data merupakan suatu upaya dalam menguraikan suatu masalah atau focus kajian menjadi bagian-bagian sehingga susunan dan tatanan bentuk sesuatu yang diurai tersebut tampak dengan jelas terlihat dan mudah dicerna atau ditangkap maknanya ${ }^{9}$. Kriteria keabsahan data yang dipakai dalam penelitian kualitatif ini yaitu dengan: 1. kepercayaan (credibility), 2. keteralihan (transferability), 3. ketergantungan (dependability), 4. kepastian (confirmality). Dan dalam pelaksanaannya yang menjadi tolak ukur dalam kepercayaan pada dasarnya menggantikan konsep validitas internal dari penelitian non kualitatif. Yang berfungsi untuk melaksanakan inkuiri dengan sedemikian rupa sehingga tingkat kepercayaan dalam penemuannya dapat tercapai dan memunculkan kepercayaan dari hasil-hasil penemuan dengan suatu pembuktian yang dilakukan oleh peneliti yang terjadi dalam kenyataan ganda yang sedang diteliti ${ }^{10}$.

\section{HASIL DAN PEMBAHASAN}

Peranan BMT sebagai lembaga keuangan tidak pernah terlepas dari sumber daya insaninya. Bahkan BMT sebagai lembaga keuangan, yang memberikan pandangan bahwa BMT mempunyai sumber daya insani yang memiliki efektivitas dan efisiensi yang tinggi,

\footnotetext{
${ }^{7}$ Basrowi dan Suwandi, Memahami Penelitian Kualitatif, Jakarta: Rineka Cipta, 2008, 142.

8 Ibid, 144.

${ }^{9}$ Hengki Wijaya. "Analisis Data Kualitatif Ilmu Pendidikan Teologi”, Sekolah Tinggi Theologia, Jaffray, 2018.

${ }^{10}$ Hengki Wijaya. "Analisis Data Kualitatif Ilmu Pendidikan Teologi”, Sekolah Tinggi Theologia, Jaffray, 2018,
} 
serta berakhlak baik. Banyaknya nasabah yang lebih memilih BMT UGT Sidogiri karena karyawannya memiliki talenta dan akhlak yang baik. Oleh karena itu, sangat diperlukan manajemen atau pengelolaan sumber daya insani yang harus dilakukan dengan sebaikbaiknya, mulai dari perencanaan sumber daya insani, analisis rancang bangun atau prosedurnya, sampai pada berbagai kendala dalam perekrutan. Tentunya ketentuan atau syarat-syarat juga sudah ditetapkan.

Dalam perekrutan karyawan di BMT UGT Sidogiri Cabang Kraksaan menggunakan sistem internal dan eksternal yang disesuaikan dengan prosedur yang terdapat dalam lembaga BMT. Kemudian informasi atau pengumuman mengenai perekrutan karyawan dipublikasikan melalui media internet, dan group alumni. Dalam merekrut tenaga kerja, tentunya setiap lembaga memiliki standar tersendiri yang disesuaikan dengan penilaian yang ada pada lembaganya. Adapun penyampaian oleh kepala BMT UGT Sidogiri Cabang Kraksaan bapak Abdul Latif dalam perekrutan yang ada di BMT itu mencari dari sumbersumber internal yang mencakup karyawan yang ada sekarang yang dapat dicalonkan untuk di promosikan nantinya atau di pindahtugaskan, serta dari karyawan yang dulu pernah bekerja menjadi pegawai dipanggil kembali. Sedangkan karyawan yang dari eksternal pihak BMT UGT Sidogiri mencakup orang-orang yang saat ini bukan merupakan anggota organisasi. Manfaat rekrutmen eksternal adalah jumlah pelamar yang lebih banyak dapat direkrut. Serta akan terdapat ide-ide, teknik kerja, metode produksi, atau pelatihan yang baru ke dalam organisasi yang nantinya akan menghasilkan pengetahuan baru kedalam profitabilitas.

Namun ada permasalahan dan keunikan atau fenomena yang terdapat dalam BMT UGT Sidogiri Cabang Kraksaan dalam segi sumber daya insaninya yaitu pengelola BMT UGT Sidogiri Cabang Kraksaan yang berlatar belakang pendidikan bukan sarjana. Tetapi tentunya pihak BMT mempunyai alasan sendiri dalam pengelolaannya, alasan tersebut disampaikan oleh kepala BMT bapak Abdul Latif dimana alasannya adalah 1. Pemahaman mengenai keilmuan perbankan syariah tidak harus dari lulusan sarjana, karena ilmu bisa di dapatkan dengan cara pelatihan, 2. Lebih mengedepankan alumni Pondok Pesantren Sidogiri karena sikap jujur, amanah, dan mempunyai akhlak yang baik, 3. Memutus pengangguran alumni Pondok Pesantren Sidogiri. Dengan alasan tersebut tentunya sangat berkesan dan menjadi ciri khas tersendiri yang membedakan dengan Koperasi BMT lain serta dapat memberi contoh yang baik bagi yang lain. Selain itu, didalam proses perekrutan karyawan di BMT UGT Sidogiri Cabang Kraksaan, ada hal yang penting yaitu pendidikan dimana tujuannya adalah untuk melihat keilmuan setiap karyawan yang telah diperolehnya dan tentunya dilihat dari calon karyawan lembaga keuangan lainya yang memang lebih mengedepankan calon karyawan dengan lulusan sarjana perbankan syariah, dan sarjana ekonomi syariah.

Namun dalam penerimaan karyawan di BMT UGT Sidogiri mempunyai perbedaan tersendiri terkait itu, karena sarjana lulusan Perbankan syari'ah dan Ekonomi syari'ah banyak yang tidak bisa masuk di BMT. Dalam BMT UGT Sidogiri Cabang Kraksaan untuk 
karyawan yang bekerja didalamnya dipenuhi atau diisi dengan karyawan yang bukan dari lulusan perbankan syariah, ekonomi syariah maupun sarjana umum lainnya. Karena semua karyawan yang bekerja disana itu 100\% dari sekolah lanjutan tingkat atas (SLTA). Hal yang sama juga dipertegas oleh kepala BMT UGT Sidogiri Cabang Kraksaan yaitu bapak Abdul Latif bahwa di BMT mayoritas sumber daya insaninya adalah lulusan SLTA semua, tapi kemudian dari semua sumber daya insani itu dilakukan pengertian dan pemahaman mengenai perbankan syariah dengan cara pelatihan mengenai perbankan syari'ah.

Di BMT UGT Sidogiri Cabang Kraksaan masih mempertahankan karyawan dengan lulusan SLTA dengan banyak asumsi yang disampaikan oleh pihak manager. Sebenarnya di BMT UGT Sidogiri Cabang Kraksaan tidak hanya lulusan SLTA yang bisa masuk, sarjana umum juga bisa masuk sebagai karyawan BMT, apalagi lulusan perbankan syariah atau ekonomi syariah yang memang sesuai dengan bidangnya. BMT UGT Sidogiri sebenarnya membuka peluang kerja bagi lulusan sarjana syari'ah untuk masuk di BMT, tetapi pada kenyataan di lapangan yang disampaikan oleh bapak Abdul Latif selaku manager di BMT kita sebenarnya sangat menerima jika ada lulusan Perbankan syari'ah, ekonomi maupun sarjana umum bisa masuk dalam Koperasi kita, namun kita lebih memprioritaskan alumni Sidogiri yang minimal lulusan SLTA karena bukan hanya mengenai kemampuan yang dipertimbangkan dalam bidang perbankan syariah tetapi juga mempertimbangkan loyalitasnya karena itu menjadi hal penting yang perlu ada di setiap karyawan, agar karyawan tidak pindah ke perusahaan atau organisasi lain. Oleh sebab itu, kami lebih memprioritaskan alumni tetapi dengan garis besar lulusan tersebut diharuskan berada di wilayah ruang lingkup tempat kantor BMT kita, jadi selama masih ada calon karyawan yang alumni Pondok Pesanten Sidogiri dan berada di wilayah kantor BMT maka kita tidak bisa menerima karyawan yang dari luar, tetapi jika tidak terdapat calon karyawan yang seperti itu maka karyawan yang akan diterima nantinya adalah yang dari luar dengan catatan kepala BMTnya tetap alumni Pondok Pesantren Sidogiri. Hal ini sesuai dengan pendapat Siagian (2010), bahwa loyalitas merupakan suatu kecenderungan karyawan untuk tidak pindah ke perusahaan atau organisasi lain sebab loyalitas dapat mempengaruhi pada kenyamanan karyawan untuk bekerja pada suatu perusahaan atau organisasi yang pada gilirannya akan berpengaruh pada kinerja.

BMT UGT Sidogiri Cabang Kraksaan dalam merekrut sumber daya insani lebih mengutamakan profesionalitas seorang pekerja muslim, dimana sikap profesional haruslah terdapat di dalamnya sifat amanah, terpercaya dan tentunya bertanggung jawab, bekerja dengan kesungguhan dan melimpahkan segala kemampuan yang telah dimilikinya demi untuk mewujudkan tujuan organisasi, bukan hanya mencari keuntungan pribadinya. Sehingga muncul jiwa amanah yaitu mampu menjalankan tugas dan bertanggung jawab atas tugasnya.

Dalam proses pengangkatan pegawai di BMT harus berdasarkan kepatutan dan kelayakan calon karyawan atau sumber daya insani atas pekerjaan yang akan dijalaninya. 
Sumber daya insani yang baik adalah suatu individu muslim yang memiliki kemampuan dengan motivasi yang tinggi dan tentunya diilhami oleh sifat-sifat Rasulullah SAW yang menjadi kriterianya, sifat-sifatnya antara lain: 1. Siddiq (Benar), 2. Amanah (Terpercaya/Jujur), 3. Tabligh (Transparan), 4. Fathanah (Cerdas), 5. Istiqamah (Teguh Pendirian). Oleh karena itu, karyawan yang diberikan amanah oleh pimpinan harus melaksanakan tugas sesuai keahlian, etos kerja yang tinggi dan amanah serta tanggung jawab sepenuhnya. Sikap amanah bisa dilihat dari hasil kinerjanya apakah sudah sesuai dengan amanah jabatan apa belum, sehingga terkait penilaian akan berjalan dan bisa dilihat hasil penilaian apakah sudah sesuai apa belum. Jadi, pihak BMT akan menyaring dan menyeleksi apakah layak untuk diterima atau dipertahankan. BMT UGT Sidogiri Cabang Kraksaan sumber daya insaninya adalah berlatar belakang lulusan SLTA yang pernah menempuh ilmu di Pondok Pesantren Sidogiri, hal ini menjadi keuntungan tersendiri di dalam sumber daya insani di BMT UGT Sidogiri, karena sudah memahami mengenai menjadi sumber daya insani yang baik sesuai ajaran seorang Umat Muslim. Tetapi, pihak BMT perlu menyesuaikan diri antara bidang yang ditekuni dengan pondasi dalam hal menjadi sumber daya insani yang baik. Dimana BMT diharuskan mampu menyesuaikan diri dengan perkembangan Zaman bahwa tidak dapat dipungkiri bahwa dalam pengelolaan lembaga keuangan syari'ah harus menguasai keilmuan perbankan syari'ah secara profesional. Profesional adalah tingkat penguasaan dan pelaksanaan terhadap knowledge, skill, dan character. Seorang yang profesional akan mempunyai tingkat tertentu pada ketiga bidang tersebut.

Dalam realita yang sudah terjadi di BMT UGT Sidogiri Cabang Kraksaan yang mayoritas bukan dari lulusan sarjana melainkan dari lulusan SLTA yang telah dibahas dalam pembahasan sebelumnya, BMT UGT Sidogiri hanya bisa memberikan pendidikan mengenai keilmuan syari'ah dengan mengadakan pelatihan untuk meningkatkan kualitas sumber daya insaninya dengan tujuan untuk memahami tentang keilmuan perbankan syari'ah karena sejatinya keilmuan yang dimiliki oleh setiap orang itu bisa di peroleh dari berbagai cara untuk memperoleh suatu ilmu pengetahuan. Pihak BMT UGT Sidogiri Cabang Kraksaan mempunyai setiap karyawan yang mempunyai kemampuan keilmuan yang sesuai bidangnya. Seperti yang disampaikan oleh bapak Abdul Latif bahwasannya BMT di isi bukan dari lulusan sarjana tetapi BMT berusaha untuk memberikan pelatihanpelatihan dan pengevaluasian agar faham terkait keilmuan perbankan syari'ah. Pelatihan yang dilakukan di BMT UGT Sidogiri Cabang Kraksaan dilakukan setiap akhir tahun, dimana pelatihan dilakukan selama 5 hari yang dilakukan di Kantor Pusat yang bertempat kota Pasuruan. Namun jika ada pelatihan selanjutnya sangat dibutuhkan maka pihak BMT dapat melakukan pelatihan lagi guna menciptakan efektivitas, efesiensi dan produktivitas terhadap koperasi BMT. Sedangkan terkait evaluasi yang dilakukan di BMT UGT Sidogiri itu mencakup evaluasi karyawan dan evaluasi kepala BMT. Evaluasi karyawan dilakukan setiap hari pada saat awal masuk kerja dan ketika akan pulang kerja, untuk evaluasi 
kepala dilakukan setiap akhir bulan yang dilakukan dari rumah ke rumah setiap kepala pimpinan guna evaluasi berjalan kondusif serta terjalin akan silaturahminya.

Dari beberapa program yang telah dilakukan oleh pihak BMT di atas, BMT mempunyai tujuan untuk mencapai tujuan lembaga keuangan syariah yang memiliki daya saing tinggi. Dimana tujuan dalam pelatihan dan evaluasi tersebut adalah untuk mempersiapkan, memperbaiki dan meningkatkan kemampuan karyawan. Kemampuan yang dimaksud yaitu : 1). Kemampuan dalam menarik nasabah serta memahami secara betul hubungan yang terjadi antara Koperasi BMT dan nasabah. 2). Kemampuan dalam memberikan layanan perbankan dengan cepat dan berkualitas. 3). Kemampuan dalam mencari peluang investasi yang tepat serta mampu mempelajari, mengevaluasi, mengimplementasikan, dan menindaklanjutinya dalam rangka melakukan pengawasan yang berbasis syariah.

Hasil penelitian ini menunjukkan bahwa BMT UGT Sidogiri Cabang Kraksaan telah melakukan sistem rekrutmen dengan jalur eksternal maupun internal yang masingmasing sumber dan metodenya. Setiap sumber dan metode tentunya mempunyai kelebihan dan kekurangannya tersendiri, dengan pengaplikasian dua metode tersebut maka kemungkinan untuk mendapat karyawan yang berkompeten akan mempunyai peluang semakin besar untuk BMT UGT Sidogiri Cabang Kraksaan. Dan dalam memperoleh karyawan yang professional pihak BMT mempunyai strategi dan komponen khusus agar karyawannya mampu melaksanakan tugas sesuai petunjuk pelaksanaan dan petunjuk teknis yaitu dengan strategi evaluasi dan pelatihan.

\section{KESIMPULAN}

1. Sistem rekrutmen di BMT UGT Sidogiri Cabang Kraksaan sangat baik dengan menggunakan dua metode yaitu rekrutmen secara internal dan eksternal. Disamping itu ada pertimbangan khusus dalam sistem rekrutmen, dimana pertimbangan tersebut adalah diutamakan calon karyawan dari Alumni Pondok Pesantren Sidogiri yang tidak diharuskan lulusan perbankan syariah dan ekonomi syariah. Karena yang terpenting dalam menjadi karyawan BMT UGT Sidogiri Cabang Kraksaan ialah ikatan batin sehingga akan memunculkan karyawan yang memiliki loyalitas tinggi terhadap organisasi. Oleh sebab itu, dari penggunaan metode dan pertimbangan khusus tersebut pihak BMT dapat menemukan sumber daya insani yang memiliki loyalitas yang tinggi dan kemampuan yang bisa dikembangkan.

2. Sedangkan dalam proses pemenuhan tuntutan profesionalitas BMT UGT Sidogiri Cabang Kraksaan menggunakan strategi dengan cara pelatihan dan evaluasi. Dimana pelatihannya dilakukan di Akhir tahun yang dilakukan selama 5 hari dan evaluasinya dilakukan setiap hari untuk karyawan dan setiap bulan untuk kepala BMT. 


\section{DAFTAR PUSTAKA}

Ali Hardana. "Manajemen Sumber Daya Insani," Al-Mashraf: Jurnal Ilmu ekonomi dan Keislaman, 3.12015.

Adib Khusnul Rois, “Analisis Sumber Daya Insani (SDI) di Bayt Al-Mal Wa Al-Tamwil (BMT),” (Tesis, IAIN, Ponorogo, 2018).

Ade Irfan Noviyanto, “Analisis Mekanisme Penerimaan Sumber Daya Insani (SDI) di KSPPS BMT Marhamah Wonosobo" ( Tesis, UIN Walisongo Wonosobo, Wonosobo, 2017).

Ahmad Murois, "Peningkatan Profesionalisme Sumber Daya Insani (SDI) Di BMT SM NU Pekalongan" (Skripsi, IAIN Pekalongan, Pekalongan, 2010)

Aji Damanuri, Metodologi Penelitian Muamalah, Ponorogo: STAIN Po PRESS, 2010.

Basrowi dan Suwandi, Memahami Penelitian Kualitatif, Jakarta: Rineka Cipta, 2008.

Firman, "Penelitian Kualitatif dan Kuantitatif”. Jakarta: Bumi Aksara 2018.

Hengki Wijaya. "Analisis Data Kualitatif Ilmu Pendidikan Teologi”, (Sekolah Tinggi Theologia, Jaffray, 2018)

Jonathan Sarwono, Metode Penelitian Kuantitatif dan Kualitatif, Yogyakarta: Graha Ilmu, 2006.

Jusmaliani, Pengelolaan Sumber Daya Insani, Jakarta: Bumi Aksara, 2014.

Lubis, Y., Hermanto, B., \& Edison, E. Manajemen dan Riset Sumber Daya Manusia. Bandung: Alfabeta. 2018.

Lexy J Moleong. “Metodelogi Penelitian Kualitatif”, Bandung: PT. Remaja Rosdakarya, 2014.

Maryani, Ay. Analisis Pengaruh Kompetensi Syari'ah, Kompensasi Islami dan Kecerdasan

Spiritual terhadap Kinerja Karyawan, Jurnal Vol 1, (online), Mei 2017. http://www.UIN

Syarifhidayatullah,ac,id, (Diakses tanggal 22 Februari 2020 jam 14.00 WIB).

Marwansyah, "Manajemen Sumber Daya Manusia", Bandung: Alfabeta, 2010.

Rudiasa, "Pengertian SDI", http://ainice.blogspot.com/2015/10/pengertian-sumber-dayainsani-sdi.html (diakses tanggal 08 Maret 2020, jam 21.50 WIB).

Samsuni, "Manajemen Sumber Daya Manusia", Al-Falah: Jurnal Ilmiah Keislaman dan Kemasyarakatan, 17.12017.

Sondang P. Siagian, Manajemen Sumber Daya Manusia, Jakarta: Bumi Aksara, 2016.

Syamsuddin AR, Vismaia S. Damaianti, Metode Penelitian Pendidikan Bahasa, Bandung: Remaja Roda Karya. 2011.

Suharsimi Arikunto, Prosedur Penelitian: Sebuah Pendekatan Praktek, jakarta: Rineka Cipta, Edisi Revisi V, 2002.

Yusuf, Burhanudin. Manajemen Sumber Daya Manusia di Lembaga Keuangan Syari'ah, Jakarta : PT. Raja Grafindo, 2015. 